\title{
COMPUTING RAM INDICES FOR RELIABLE OPERATION OF PRODUCTION SYSTEMS
}

\author{
Sharma Kumar Rajiv* \& Sharma Pooja** \\ ${ }^{*}$ Associate Professor, Department of Mechanical Engineering, National Institute of \\ Technology, NIT Hamirpur, Himachal Pradesh, 177005 India \\ ${ }^{*}$ Department of Computer Science and Engineering, National Institute of Technology, \\ NIT Hamirpur, Himachal Pradesh, 177005 India \\ E-mail: rksfme@nitham.ac.in
}

\begin{abstract}
:
Purpose: The purpose of this paper is to permit the system reliability analysts/managers/engineers/ practitioners to conduct RAM analysis of the system which may helps them to model, analyze and predict the behavior of industrial systems in a more realistic and consistent manner. Design/methodology/approach: Markovian approach is used to model the system behavior. For carrying out study, Root Cause Analysis (RCA) of the subsystems is carried out and transition diagrams for various subsystems are drawn and differential equations associated with them are formulated. After obtaining the steady state solution the corresponding values of reliability and maintainability are estimated at different mission times. Findings: With RAM analysis of the system key performance metrics such as Mean Time between Failure (MTBF), Mean time to Repair Time (MTTR) and System availability values are ascertained. Research limitations/implications: Based on the RAM analysis, possible maintenance strategies can be investigated which might help the plant personnel to improve the system effectiveness. Practical Implications: Without exercising much effort in developing complex system models, the proposed method for analyzing system performance may prove helpful to the reliability analysts/ engineers/practitioners to model analyze and predict the behavior of system more efficiently and resolve the RAM requirements of the system in unison. Originality/value: The simultaneous adoption of both qualitative (RCA) and quantitative (Markov approach) approach to analyze and obtain RAM indices for measuring the system performance helps the maintenance engineers to improve RAM aspects after understanding the failure behavior of component(s) in the system.
\end{abstract}

Key Words: Markov, System Failure, Reliability, Maintainability, Process Industry

\section{INTRODUCTION}

Various innovative techniques and management practices such as, Total productive maintenance (TPM), Total quality management (TQM), Business process reengineering (BPR), Material requisite planning (MRP), Supply Chain Management (SCM) and Just in Time (JIT) etc. are being used as drivers by the business houses to promote their products and processes [1-3]. But there is no doubt that the success of these innovative programs mainly depends upon the reliable operation of production systems. A company cannot achieve success if its systems are unavailable and unreliable. Increasingly, companies are viewing reliability and maintainability issues as part of the corporate quest to improve quality by imbibing lean manufacturing, just in time, six-sigma mantras to achieve customer satisfaction and remain competitive $[2,4]$. The management is highly concerned with reliable operation of production systems. To this effect the knowledge of behavior of system, their component(s) is customary in order to plan and adapt suitable maintenance strategies. For the last 04 decades reliability analysis has been established as a useful tool for risk analysis, production availability studies and design of systems [6-9]. Reliability techniques have been applied in three main areas in process industry(i) production availability studies in conceptual design (RAM analysis) (ii) safety (risk analysis) (iii) maintenance (criticality analysis, life cycle 
cost) [10]. Much effort has been made to compile and analyze reliability data for generic use. For instance, Cochran et al. [7] presented a practical case study of reactor regenerator system in Fluid Catalytic Cracking Unit of a petroleum refinery using generic Markov models to estimate system availability. Liberopoulos and Tsarouhas [8] presented a statistical analysis of failure data of an automated pizza production line. The analysis includes identification of failures, computation of statistics of the failure data, and parameters of the theoretical distributions that best fit the data, and investigation of the existence of autocorrelations and cross correlations in the failure data. The analysis is meant to guide food product machinery manufacturers to improve the design and operation of the production lines. Dai and Jia [11] collected failure data of vertical machining center ,analyzed it and based on the analysis provided ways to improve the reliability of machining centre. Schoenig et al., [12] presented an aggregation method using markov graphs for the reliability analysis of hybrid systems. The method allows the designers to have an exact representation and better overview of the system states. Gupta et al.,[13] analysed reliability and availability of serial processes of plastic-pipe manufacturing plant. In the study they computed reliability, availability, and mean time before failure of the process of a plastic-pipe manufacturing plant consisting of a $(K, N)$ system for various choices of failure and repair rates of sub-systems by setting up Chapman-Kolmogorov differential equations. Pari et al., [14] conducted reliability improvement study of electronics standby display system of modern aircraft. Through this analysis they made an attempt to improve the reliability of an electronic stand by display system (ESDS) used in the cockpit. Saraswat and Yadava [15] in their paper emphasised on reliability, availability, maintainability and supportability (RAMS) aspects for improving performance of engineering systems. Vallem, and Saravannan, [16] used fault tree analysis to assess reliability of cogeneration power plant in textile mill. Sharma et al. [17] developed an integrated framework to optimize RAM and cost decisions in a process plant. As evident from the above literature studies that much effort has been made to develop system models to solve the problems related to availability and reliability of systems. Owing to their complexity, the production systems are generally vulnerable to various kinds of disturbances, the nature (hydraulic, pneumatic, electronic and electrical), the number of failures and the time required to locate them. These failures not only add to downtime but also incur additional operation and maintenance costs. Quickly finding out the cause(s) of failure(s) and taking appropriate remedial actions is very important. Root cause analysis (RCA), a problem solving method aimed at identifying the root causes of problems or events. RCA is based on the belief that problems are best solved by attempting to correct or eliminate root causes and not by just considering the immediately obvious symptoms. By directing corrective measures at root causes, it is hoped that the likelihood of problem recurrence will be minimized.

The paper presents an illustrative case from an industry engaged in garment manufacturing. In the first phase, qualitative analysis of dyeing unit is carried out by using RCA. In the second phase, RAM analysis is carried out to obtain RAM indices for assessing system performance. The dyeing unit is considered as a system consisting of six subsystems connected in series. With RAM analysis of the system key performance metrics such as Mean Time between Failure (MTBF), Mean time to Repair (MTTR) and System Availability $\left(A_{\text {sys }}\right)$ are ascertained. The information obtained from the analysis helps the management in assessing of the reliability, availability and maintainability needs of system. Based upon Markov modeling, all the system units are modeled to obtain RAM indices for measuring the system performance so that a companywide maintenance planning system could be made for effective maintenance and operation of system.

\section{SYSTEM DESCRIPTION AND ASSUMPTIONS}

Study is undertaken for garment manufacturing company with a present annual turnover of 350 crores. The company considered in the study currently manufactures readymade garments for kids, women and men, in addition to yarn for other manufacturers. Its product range includes thermal wear, T-shirts, trousers, track suits, pullovers, shorts, casuals and 
jackets. These products are manufactured from raw material like cotton, fiber. First the thread is manufactured in the spinning mill \& then dyeing is done in the Dyeing unit \& after that garments are manufactured in the next unit. At present the company has a capacity of 85000 spindles, dyeing capacity of 12 tones and yarn making capacity of 80 tons per day. Company is embarking upon a major expansion plan enhancing its spindle \& dyeing capacities and setting up a $15 \mathrm{MW}$ power generation plant. Figure 1 shows system configuration with various units.

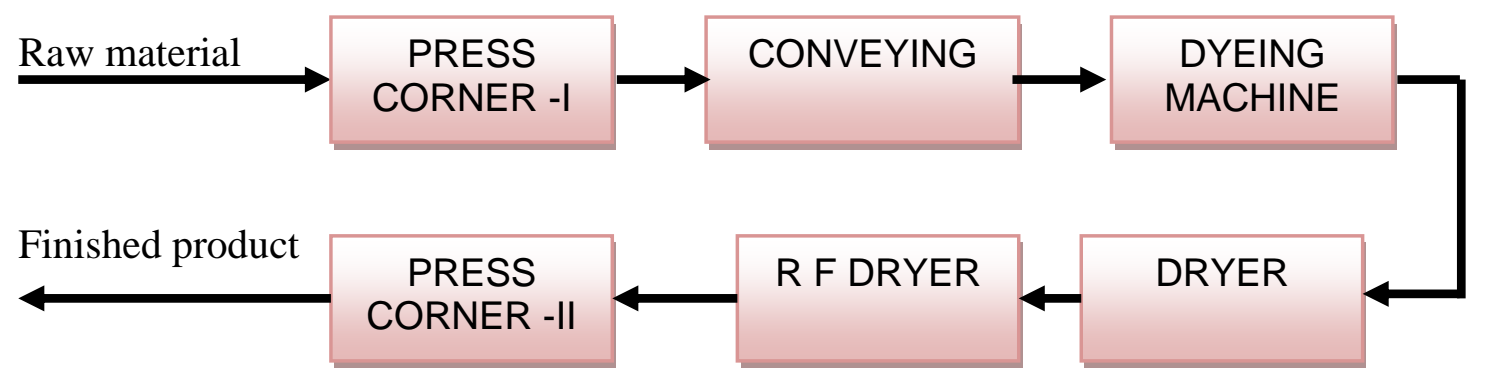

Figure 1: System units.

The raw material for this system is thread which passes through the following six stages:

Stage 1. Rolling of thread on spring

The raw product for the plant is thread, which is mounted on the paper cones. These threads from the cones are mounted on the stainless steel springs also called 'soft packages' with the help of press corner machine. This is done so that when dyeing is done then these springs would be able to withstand high temperature and pressure.

Stage 2. Loading of spring on carrier

Springs (Soft packages) are then loaded on the individual spindle of the carrier of Dyeing machine and these packages are pressed to make uniform column to get even dyeing. Then, this carrier is carried to the Dyeing container through a conveying system which is remote operated.

Stage 3. Dyeing of threads

After placing the carrier inside the dyeing machine, it is closed and dye is inserted in the machine by the injector pump. A suitable temperature and pressure ranges are maintained and main pump is started. Then the dyeing process takes place. First the dye is diffused in the thread from inside the soft packages and after some time it is diffused from outside to inside for uniform dyeing.

Stage 4. Drying of spring

The dyed yarn soft packages are put in Hydro Extractor which removes moisture by the centrifugal process, but still some moisture is left in the threads. So these threads are dried in the Radio Frequency Dryer.

Stage 5. Radio Frequency drying

Moisture content of the yarn after passing through Hydro Extractor is about $48-52 \%$ and such packages are then passed through RF Dryer to remove the balance moisture of the package. The resultant moisture after passing through RF Dryer is about $7-8 \%$. Drying is done with the help of microwaves.

Stage 6. Rolling of threads on paper cones

As the thread is dry now so springs are put again on the press corner machine and then thread is mounted again on the paper cones. Finally, each individual cone is checked for any quality defects by visual inspection under light and then it is packed for final shipment.

\section{Assumptions}

For the purpose of modeling to obtain RAM indices, following assumptions were taken into account 
1. Failure rates \& repair rates for all the units of thread dyeing plant sub-systems are constant over time.

2. Mean Time Between Failure (MTBF) \& Mean Time To Repair (MTTR) data are exponentially distributed. So, there are no simultaneous failures of units in sub-system or among the sub systems \& probability of more than one failure or repair in a time interval is zero.

3. The repaired units are as good as new one. Repair or replacement carried out in case of failure only.

4. There are separate repair facilities for each sub system.

5. Any sub system of the thread dyeing plant remains only in only two of the states: operating and non-operating.

The study described in the paper is for the steady state period i.e. during which the failure rate of the system can be considered as constant (as shown in Figure 2 by the Bath-tub curve). The definitions for reliability, availability and maintainability used to obtain RAM indices are provided in $[18,20]$.

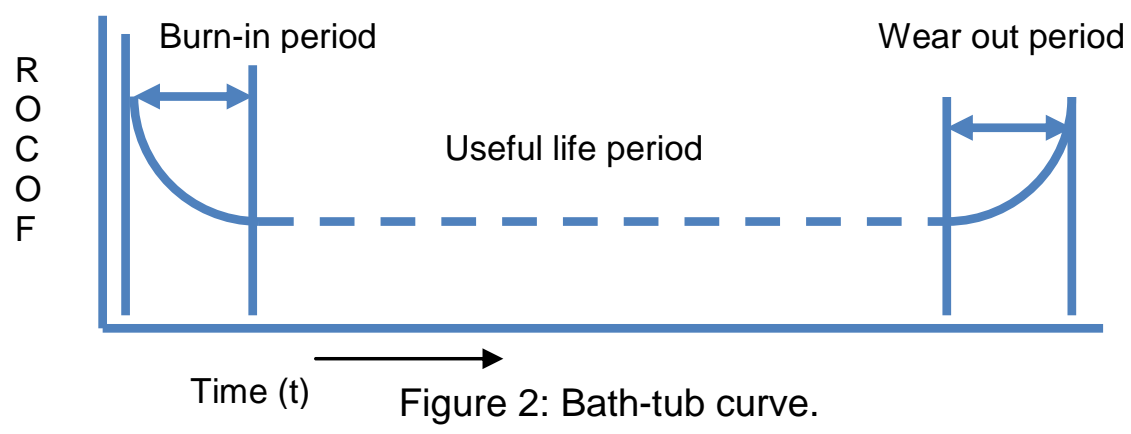

\section{SYSTEM ANALYSIS}

Before conducting quantitative analysis to determine the RAM indices, qualitative analysis of the system is carried out using Root Cause Analysis. Figure 3 shows RCA diagram for conveying sub-system. Similarly, RCA is carried out for other subsystems i.e. Dyeing Machine, Spin Dryer, Radio Frequency Dryer and Press Corner-II.

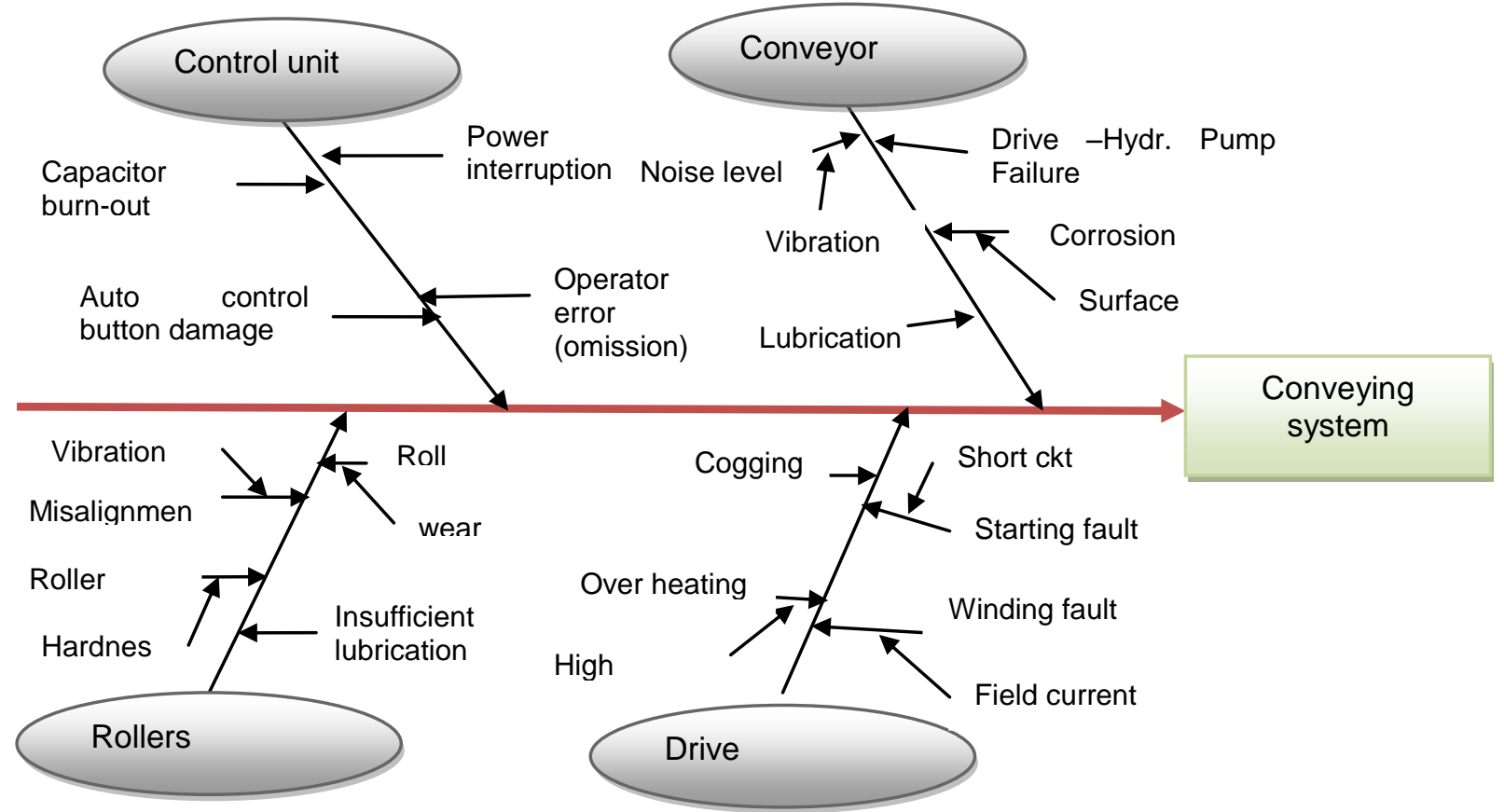

Figure 3: Root Cause Analysis for Conveying Sub-System. 
Conveying subsystem is considered for quantitative analysis. Figure 4 shows reliability block diagram for Conveying Sub system

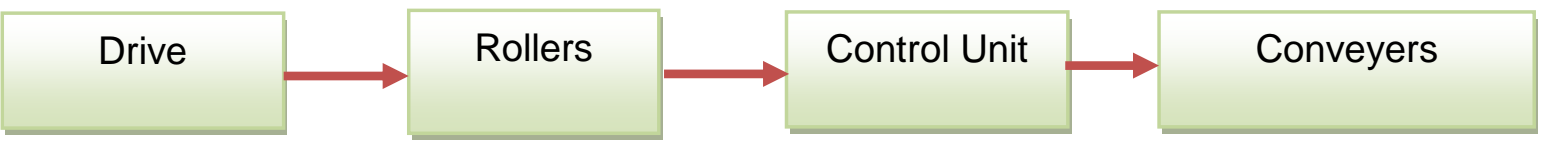

Figure 4: RBD for Conveying System.

Table I: Failure and Repair Rates of different Components.

\begin{tabular}{|c|c|c|c|}
\hline \multicolumn{2}{|c|}{ Sub Systems } & Failure Rate $(\lambda)$ & Repair Rate $(\mu)$ \\
\hline $\begin{array}{r}\text { Press } \\
0 \\
0\end{array}$ & $\begin{array}{l}\text { orner } \\
\text { Spindle bearing } \\
\text { Drive }\end{array}$ & $\begin{array}{l}0.0001016 \\
0.0005208\end{array}$ & $\begin{array}{c}1 \\
0.25\end{array}$ \\
\hline $\begin{array}{r}\text { Conv } \\
0 \\
0 \\
0 \\
0\end{array}$ & $\begin{array}{l}\text { ing System } \\
\text { Drive } \\
\text { Rollers } \\
\text { Control Unit } \\
\text { Conveyor }\end{array}$ & $\begin{array}{l}0.0002277 \\
0.0000493 \\
0.0000468 \\
0.0000256\end{array}$ & $\begin{array}{c}0.25 \\
0.50 \\
1 \\
0.33\end{array}$ \\
\hline $\begin{array}{r}\text { Dyein } \\
\circ \\
\circ \\
\\
\\
\end{array}$ & $\begin{array}{cl}\text { Machine } & \\
\text { Drive } & \\
\text { Pump } & \\
\text { - } & \text { O Ring } \\
\text { - } & \text { C Seamp Oil } \\
\text { - } & \text { Mech. Seal } \\
\text { - } & \text { Bush } \\
\text { Dyeing } & \text { Container } \\
\text { - } & \text { Lip Sealing Ring } \\
\text { - } & \text { Steam Line } \\
\text { - } & \text { Steain Valve } \\
& \text { Stean Handling System }\end{array}$ & $\begin{array}{l}0.0004386 \\
0.0001609 \\
0.0001758 \\
0.0002003 \\
0.0000865 \\
0.0000536\end{array}$ & $\begin{array}{l}0.17 \\
0.33 \\
1 \\
0.50 \\
0.50 \\
0.33\end{array}$ \\
\hline $\begin{array}{r}\text { Spin } \\
\circ \\
\circ \\
\circ \\
\circ\end{array}$ & $\begin{array}{l}\text { yer } \\
\text { Bearing } \\
\text { Drive } \\
\text { Shaft } \\
\text { Rubber Ring }\end{array}$ & $\begin{array}{l}0.0000885 \\
0.0003655 \\
0.0000477 \\
0.0000304\end{array}$ & $\begin{array}{c}1 \\
0.25 \\
0.25 \\
1\end{array}$ \\
\hline $\begin{array}{r}\text { R F D } \\
\circ \\
\circ \\
\circ \\
\circ \\
\circ \\
\circ\end{array}$ & $\begin{array}{l}\text { Cor } \\
\text { Conveyor Belt } \\
\text { Bearing } \\
\text { Shaft } \\
\text { Fan } \\
\text { Electronic components } \\
\text { Drive }\end{array}$ & $\begin{array}{l}0.0000283 \\
0.0000862 \\
0.0000528 \\
0.0001800 \\
0.0000573 \\
0.0003333\end{array}$ & $\begin{array}{l}0.083 \\
1 \\
0.25 \\
0.33 \\
0.50 \\
0.25\end{array}$ \\
\hline
\end{tabular}

\subsection{Quantitative Analysis}

For carrying out quantitative analysis to determine system RAM indices failure and repair data of different system components is collected by taking into account company's historical records and maintenance logs (Table I)

Reliability for Conveying System : $R_{C S}=R_{D}{ }^{*} R_{R}{ }^{*} R_{C}{ }^{*} R_{C}$

Reliability of Drive, $R_{D}=e^{-\lambda t}$

Reliability of Rollers, $R_{R}=e^{-\lambda t}$

Reliability of Control Unit, $R_{C U}=e^{-\lambda t}$

Reliability of Conveyer,$R_{C}=e^{-\lambda t}$

Table II presents values of reliability for all the components of conveying subsystem. 
Table II: Computed Reliability Values of units.

\begin{tabular}{|c|c|c|c|c|c|}
\hline Time (hrs.) & Drive & Rollers & Control Unit & Conveyors & $\mathbf{R}_{\text {conveying system }}$ \\
\hline 0 & 1 & 1 & 1 & 1 & 1 \\
\hline 100 & 0.97749 & 0.99508 & 0.99331 & 0.99744 & 0.96370 \\
\hline 200 & 0.95548 & 0.99019 & 0.99068 & 0.99489 & 0.93249 \\
\hline 300 & 0.93397 & 0.98532 & 0.98605 & 0.99235 & 0.90048 \\
\hline 400 & 0.91295 & 0.98047 & 0.98145 & 0.98981 & 0.86956 \\
\hline 500 & 0.89239 & 0.97565 & 0.97687 & 0.98728 & 0.83970 \\
\hline 600 & 0.87231 & 0.97085 & 0.97231 & 0.98475 & 0.81087 \\
\hline 700 & 0.85267 & 0.96608 & 0.96777 & 0.98223 & 0.78303 \\
\hline 800 & 0.83347 & 0.96132 & 0.96325 & 0.97972 & 0.75613 \\
\hline 900 & 0.81470 & 0.95659 & 0.95875 & 0.97722 & 0.73016 \\
\hline 1000 & 0.79631 & 0.95189 & 0.95427 & 0.97475 & 0.70507 \\
\hline
\end{tabular}

\section{Availability}

From the transition diagram (Figure 5) the equations derived are as follows:

$$
\begin{aligned}
& \mathrm{P}_{\mathrm{p}^{*}} \mu_{\mathrm{p}}=\mathrm{P}_{0^{*}} \lambda_{\mathrm{p}} \\
& \mathrm{P}_{\mathrm{a}^{*}} \mu_{\mathrm{q}}=\mathrm{P}_{0^{*}} \lambda_{\mathrm{q}} \\
& \mathrm{P}_{\mathrm{r}^{*}} \mu_{\mathrm{r}}=\mathrm{P}_{0^{*}} \lambda_{\mathrm{c}} \\
& \mathrm{P}_{\mathrm{s}^{*}} \mu_{\mathrm{s}}=\mathrm{P}_{0^{*}} \lambda_{\mathrm{s}}
\end{aligned}
$$

Since the sum of the probabilities will be unity, then

$$
P_{p}+P_{q}+P_{r}+P_{s}+P_{0}=1
$$

Solving for $P_{0}$;

$$
P_{0}=1 /\left(1+\sum \lambda_{i} / \mu_{i}\right)
$$

Substituting the values of $\lambda_{\mathrm{i}}$ and $\mu_{\mathrm{i}}$, the steady state availability of the Conveying System $\mathrm{P}_{0}=$ 0.999832

Reliability of the Conveying System $R=e^{-\left(\Sigma \lambda^{\star} t\right)}$

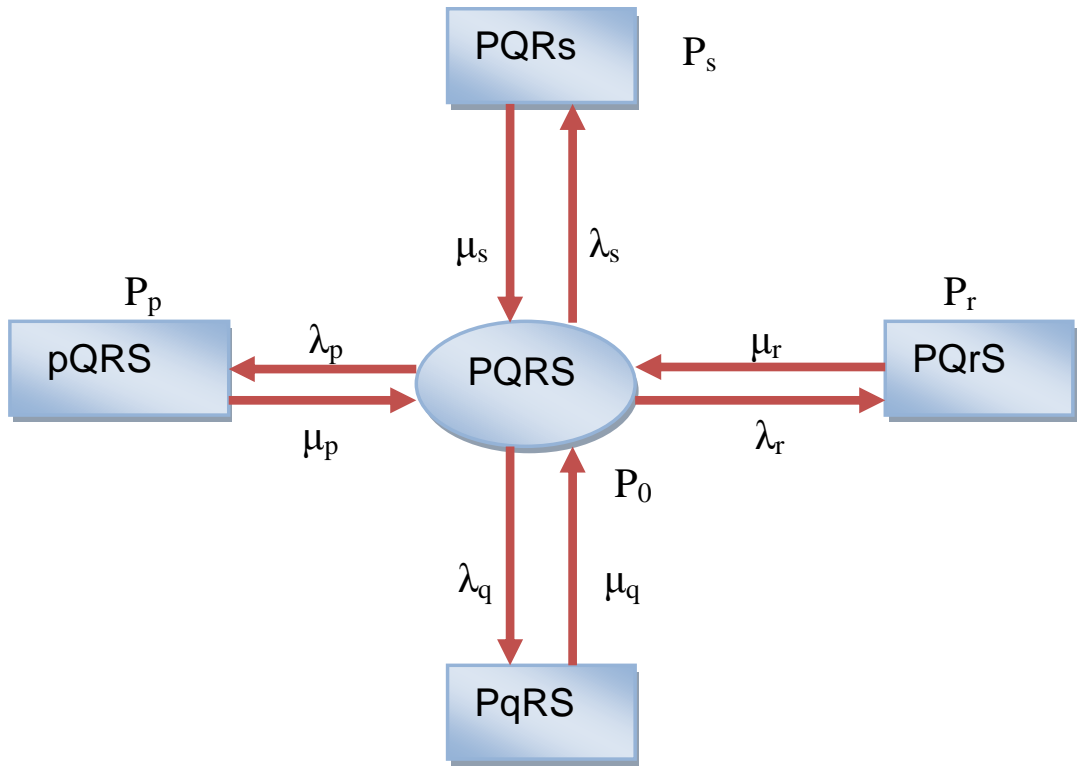

Figure 5: Transition diagram of Conveying System.

Failure rate of the Conveying System $(\lambda)=\sum \lambda_{\mathrm{i}}$

Conveying System MTBF $=1 / \lambda$

$$
=2862.05 \mathrm{hr}
$$

It is known that availability of the Conveying System $=M T B F /(M T B F+M T T R)$

Where, MTTR is the mean time to repair 
MTTR of the Conveying System $=0.48 \mathrm{hrs}$

Hence repair rate $(\mu)=1 / \mathrm{MTTR}=2.08 / \mathrm{hr}$

Therefore the maintainability of the Conveying System $=1-\mathrm{e}^{-\mu t}$

Table III presents values of maintainability for all the components of conveying subsystem

Table III: Maintainability Estimation of Conveying System.

\begin{tabular}{|c|c|c|c|c|c|}
\hline Time(hrs.) & Drive & Rollers & Remote & Conveyers & Conveying system \\
\hline 0 & 0 & 0 & 0 & 0 & 0 \\
\hline 1 & 0.22119 & 0.39347 & 0.63212 & 0.28108 & 0.26361 \\
\hline 2 & 0.39346 & 0.63212 & 0.86467 & 0.48314 & 0.45773 \\
\hline 3 & 0.52763 & 0.77686 & 0.95021 & 0.62842 & 0.60068 \\
\hline 4 & 0.63212 & 0.86466 & 0.98168 & 0.73286 & 0.70594 \\
\hline 5 & 0.71349 & 0.91791 & 0.99326 & 0.80795 & 0.78346 \\
\hline 6 & 0.77686 & 0.95021 & 0.99752 & 0.86193 & 0.84054 \\
\hline 7 & 0.82622 & 0.96980 & 0.99908 & 0.90073 & 0.88258 \\
\hline 8 & 0.86466 & 0.98168 & 0.99966 & 0.92863 & 0.91353 \\
\hline 9 & 0.89460 & 0.98889 & 0.99987 & 0.94869 & 0.93632 \\
\hline 10 & 0.91791 & 0.99326 & 0.99995 & 0.96311 & 0.95311 \\
\hline
\end{tabular}

\section{RESULTS}

The reliability and maintainability results for all the sub-systems are calculated at different mission times (i.e. $\mathrm{t}=0,100,200 \ldots \ldots \ldots \ldots . . .1000 \mathrm{hrs}$ ). Table IV (a) and (b) presents systems reliability and maintainability values. The graphical results are shown in Figure 6 (a) and (b) respectively.

Table IV: (a) Computed reliability values.

\begin{tabular}{|c|c|c|c|c|c|c|l|}
\hline Time & $\mathbf{R}_{\text {Subsystem1 }}$ & $\mathbf{R}_{\text {Subsystem2 }}$ & $\mathbf{R}_{\text {Subsystem3 }}$ & $\mathbf{R}_{\text {Subsystem4 }}$ & $\mathbf{R}_{\text {Subsystem5 }}$ & $\mathbf{R}_{\text {Subsystem6 }}$ & $\mathbf{R}_{\text {system }}$ \\
\hline $\mathbf{0}$ & 1 & 1 & 1 & 1 & 1 & 1 & 1 \\
\hline $\mathbf{1 0 0}$ & 0.93965 & 0.92489 & 0.87859 & 0.94817 & 0.92885 & 0.93965 & 0.63188 \\
\hline $\mathbf{2 0 0}$ & 0.88296 & 0.93249 & 0.77200 & 0.89903 & 0.86278 & 0.88296 & 0.43532 \\
\hline $\mathbf{3 0 0}$ & 0.82967 & 0.90048 & 0.68091 & 0.85244 & 0.80141 & 0.82967 & 0.28833 \\
\hline $\mathbf{4 0 0}$ & 0.77961 & 0.86956 & 0.59603 & 0.80827 & 0.74441 & 0.77961 & 0.18955 \\
\hline $\mathbf{5 0 0}$ & 0.73257 & 0.83970 & 0.52372 & 0.76639 & 0.69146 & 0.73257 & 0.12501 \\
\hline $\mathbf{6 0 0}$ & 0.68836 & 0.81087 & 0.45763 & 0.72668 & 0.64556 & 0.68836 & 0.08249 \\
\hline $\mathbf{7 0 0}$ & 0.64682 & 0.78303 & 0.40433 & 0.68901 & 0.59658 & 0.64682 & 0.05444 \\
\hline $\mathbf{8 0 0}$ & 0.60779 & 0.75613 & 0.35528 & 0.65331 & 0.55414 & 0.60779 & 0.03592 \\
\hline $\mathbf{9 0 0}$ & 0.57112 & 0.73016 & 0.31218 & 0.61941 & 0.51472 & 0.57112 & 0.02371 \\
\hline $\mathbf{1 0 0 0}$ & 0.53666 & 0.70507 & 0.27429 & 0.58736 & 0.47812 & 0.53666 & 0.01564 \\
\hline
\end{tabular}

\section{Availability}

Availability $=A_{p c 1}{ }^{*} A_{c}{ }^{*} A_{d m}{ }^{*} A_{s d}{ }^{*} A_{r f d}{ }^{*} A_{p c 2}$

$$
=0.999^{*} 0.999832^{*} 0.992759^{*} 0.9997872^{*} 0.99696^{*} 0.999=0.990096
$$

Failure rate of System $\left(\lambda_{S}\right)=\sum \lambda_{\mathrm{i}}$

Mean time between failures $(\mathrm{MTBF})=1 / \lambda_{\mathrm{S}}=334.694 \mathrm{hrs}$.

It is known that availability $=\mathrm{MTBF} /(\mathrm{MTBF}+\mathrm{MTTR})$ So, $\mathrm{MTTR}$ of system $=3.347 \mathrm{hrs}$

Repair rate of system $=0.2968 / \mathrm{hr}$

\section{Maintainability}

Maintainability of system $=1-e^{-\mu t}$ 


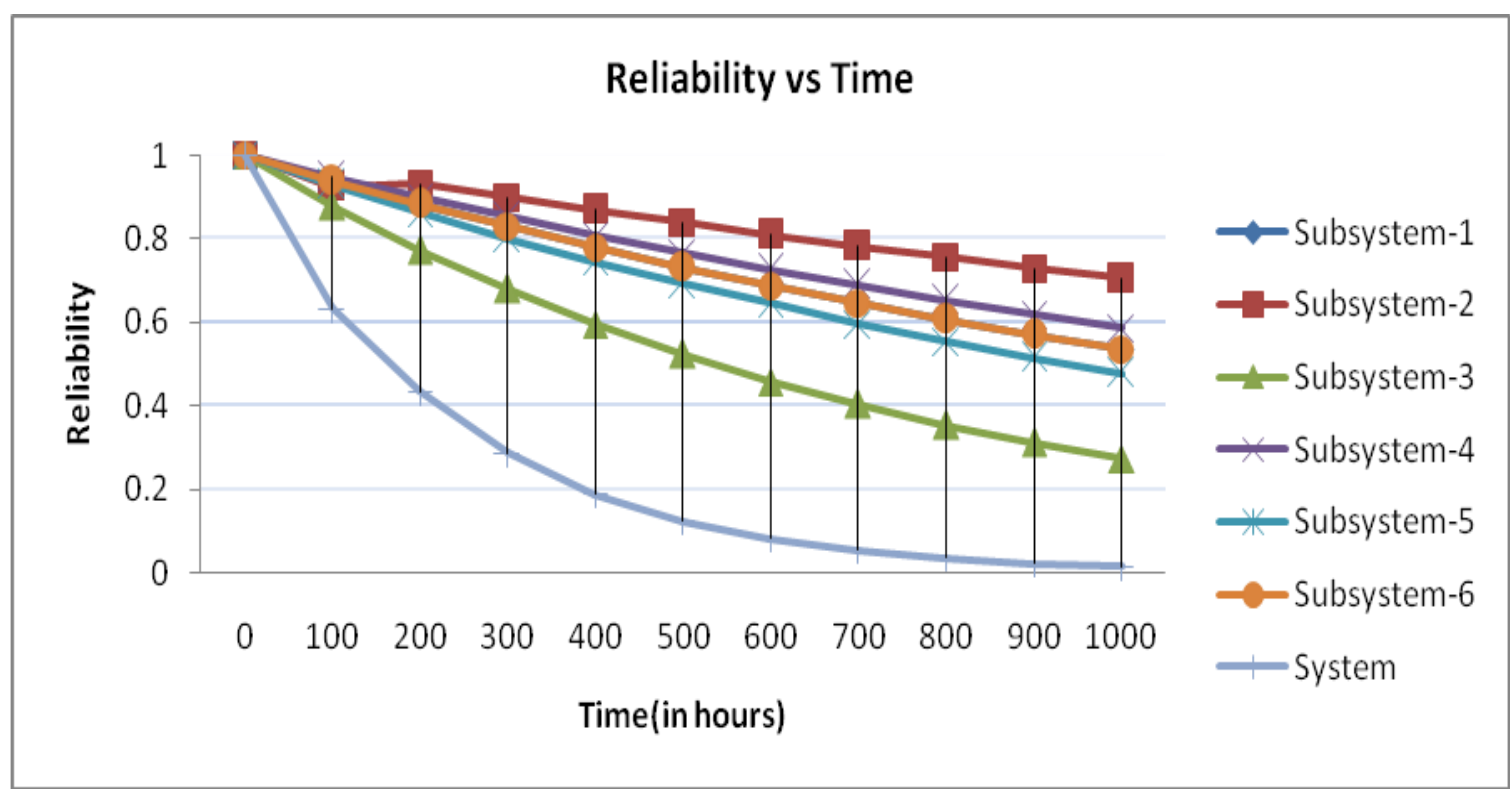

Figure 6: Reliability Curves.

Table IV (b) Computed maintainability values.

\begin{tabular}{|c|c|c|c|c|c|c|c|}
\hline $\begin{array}{c}\text { Time } \\
\text { (hrs.) }\end{array}$ & $\mathbf{M}_{\text {Subsystem1 }}$ & $\mathbf{M}_{\text {Subsystem2 }}$ & $\mathbf{M}_{\text {Subsystem3 }}$ & $\mathbf{M}_{\text {Subsystem4 }}$ & $\mathbf{M}_{\text {Subsystem5 }}$ & $\mathbf{M}_{\text {Subsystem6 }}$ & $\mathbf{M}_{\text {System }}$ \\
\hline $\mathbf{0}$ & 0 & 0 & 0 & 0 & 0 & 0 & 0 \\
\hline $\mathbf{1 0 0}$ & 0.46205 & 0.26361 & 0.19466 & 0.25546 & 0.24346 & 0.46205 & 0.25680 \\
\hline $\mathbf{2 0 0}$ & 0.71061 & 0.45773 & 0.35143 & 0.44567 & 0.42764 & 0.71061 & 0.44766 \\
\hline $\mathbf{3 0 0}$ & 0.84432 & 0.60068 & 0.47769 & 0.58728 & 0.56699 & 0.84432 & 0.58950 \\
\hline $\mathbf{4 0 0}$ & 0.91625 & 0.70594 & 0.57936 & 0.69272 & 0.67241 & 0.91625 & 0.69492 \\
\hline $\mathbf{5 0 0}$ & 0.95495 & 0.78346 & 0.66125 & 0.77122 & 0.75216 & 0.95495 & 0.77327 \\
\hline $\mathbf{6 0 0}$ & 0.97576 & 0.84054 & 0.72719 & 0.82966 & 0.81250 & 0.97576 & 0.83149 \\
\hline $\mathbf{7 0 0}$ & 0.98696 & 0.88258 & 0.78073 & 0.87318 & 0.85815 & 0.98696 & 0.87476 \\
\hline $\mathbf{8 0 0}$ & 0.99290 & 0.91353 & 0.82306 & 0.90557 & 0.8268 & 0.99290 & 0.90692 \\
\hline $\mathbf{9 0 0}$ & 0.99662 & 0.93632 & 0.85751 & 0.92970 & 0.91881 & 0.99662 & 0.93083 \\
\hline $\mathbf{1 0 0 0}$ & 1 & 0.95311 & 0.88524 & 0.94766 & 0.93857 & 1 & 0.94859 \\
\hline
\end{tabular}




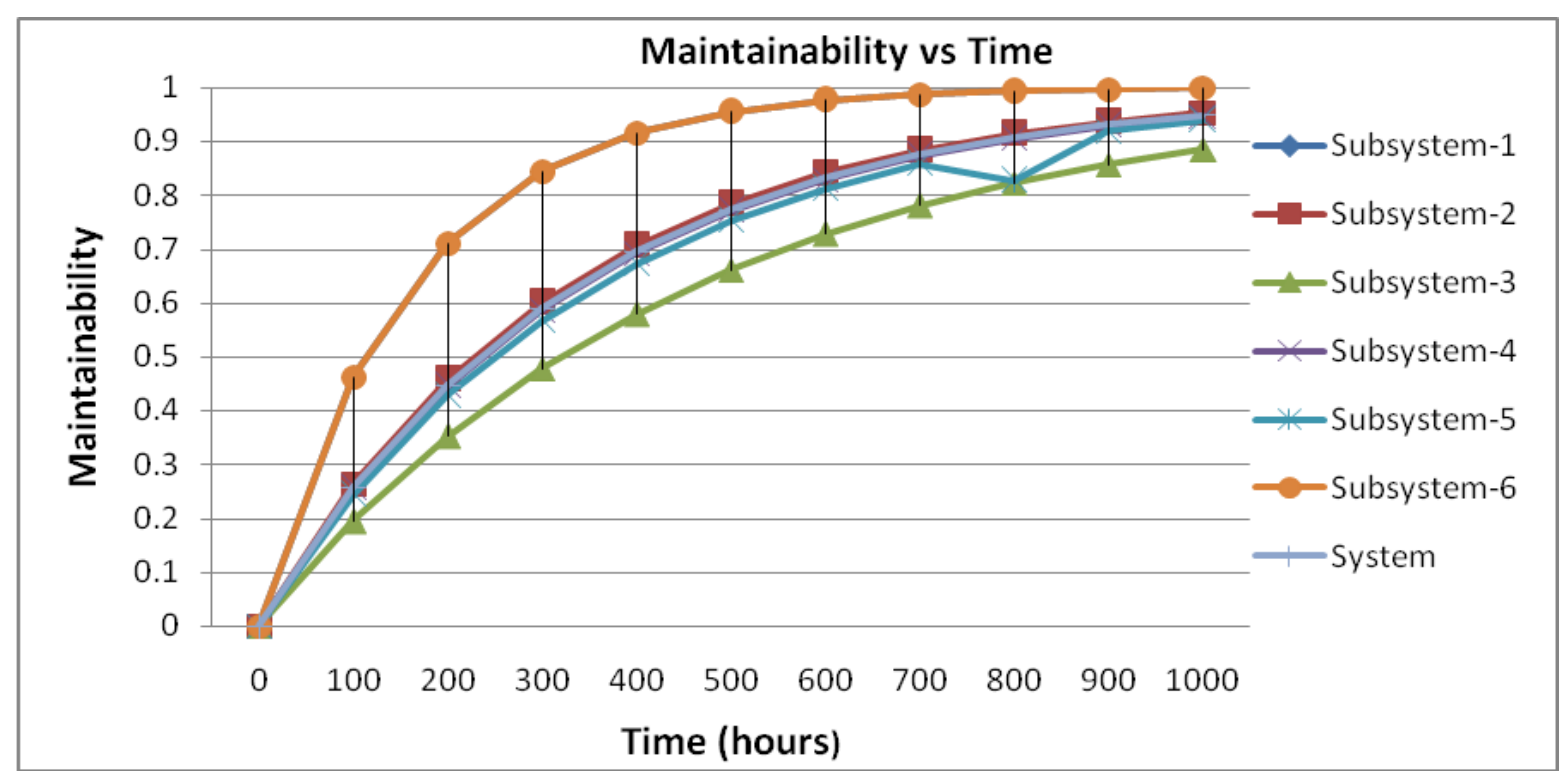

Figure 7: Maintainability curves.

\section{DISCUSSION}

From Figure 7 it is observed that probability of system non-failure for $400 \mathrm{hrs}$ is 0.189 and for subsystems the corresponding values of reliability at mission time $t=400 \mathrm{hrs}$ are, $R_{s s 1}=0.77$, $\mathrm{R}_{\mathrm{ss} 2}=0.86, \mathrm{R}_{\mathrm{ss} 3}=0.59, \mathrm{R}_{\mathrm{ss} 4}=0.80, \mathrm{R}_{\mathrm{ss} 5}=0.74$ and $\mathrm{R}_{\mathrm{ss} 6}=0.7780$ and for corresponding subsystems the maintainability values are $M_{s s 1}=0.91, M_{s s 2}=0.70, M_{s s 3}=0.57 ; M_{s s 4}=0.69 M_{s s 5}$ $=0.67 \mathrm{M}_{\mathrm{ss} 6}=0.91$ respectively. As the reliability values for unit 3 are found to be low, therefore the performance of $\mathrm{SS}_{3}$ needs special attention and careful observation. Hence, it is concluded that a preventive maintenance and repair action for the above subsystem should be strengthened to improve the overall system reliability. Reliability and Maintainability curves indicates that the performance of Dyeing Machine \& Radio Frequency Dryer are to observed carefully \& need special attention for higher performance of Dyeing Unit as a whole. The maintainability of Press Corner -I \& Press Corner -II is found better as compared to $\mathrm{SS}_{3}$ and $\mathrm{SS}_{4}$ which calls for adopting new maintenance strategies. The availability indices for different subsystems are $0.999\left(\mathrm{SS}_{1}\right), 0.999832\left(\mathrm{SS}_{2}\right), 0.992759\left(\mathrm{SS}_{3}\right)$, $0.9997872\left(\mathrm{SS}_{4}\right), 0.99696\left(\mathrm{SS}_{5}\right)$ and $0.999\left(\mathrm{SS}_{6}\right)$.

Based on the above analysis, maintenance schedule can be prepared which might help the maintenance managers to improve the system effectiveness by adopting suitable preventive maintenance actions. FMEA analysis of the system can be carried out by listing all possible failure modes with reference to different sub-systems.

\section{REFERENCES}

[1] Waeyenbergh G. and Pintelon L., Maintenance concept development a case study, Int J Prod Econ $89(3,18)(2004)$, pp. 395-405

[2] C.N. Madu, Strategic value of reliability and maintainability management, Int $J$ Qual Reliab Management Vol. 22 (3) (2005), pp. 317-328

[3] Sharma R., Kumar D.and Kumar P., Manufacturing excellence through TPM implementationa practical analysis, Industrial Management and Data Systems 106 (2) (2006), pp. 256-280

[4] Sharma R., Kumar S ., Performance modeling in critical engineering systems using RAM analysis, Reliability Engineering \& System Safety, Vol. 93, 6, 2008, pp. 913-919

[5] Arid R.J.'Application of Reliability Engineering to Process plant Maintenance', The Chemical Engineer. pp 301-311, Vol. 74, 1980

[6] Buzacott JA. 'Markov approach to find failure times of repairable systems'. IEEE Transactions on Reliability, Vol.19, 1970 
[7] Cochran, J.K., Murugan, A and Krishnamurthy, V "Generic Markov models for availability estimation and failure characterization in petroleum refineries", Computers and Operations Research, Vol 28 (1), 2000, pp.1-12

[8] Liberopoulos, G., and Tsarouhas, P., "Reliability analysis of an automated pizza production Line", Journal of Food Engineering, Vol 69 (1), 2005 , pp. 79-96

[9] Hauptmanns, U., "Semi-quantitative fault tree analysis for process plant safety using frequency and probability ranges", Journal of Loss Prevention in the Process Industries, Vol 17(5), 2004 pp 339-345.

[10] Oystein, M. Use of reliability technology in the process industry, Reliab Eng Syst Saf Vol.60 (1998), pp. 179-181..,

[11] Dai ,Y., and Jia, Y., "Reliability of a VMC and its improvement", Reliability Engineering andSystemSafety, Vol.72(1),2001,pp.99-102 [10]

[12] Schoenig, R., Aubry, J.F., Cambois, T., and Hutinet, T., "An aggregation method of Markov graphs for the reliability analysis of hybrid system" Reliability Engineering \& System Safety Vol.91(2),2006pp.137-148

[13] Gupta P, Kumar A Sharma,R K, Singh J Analysis of reliability and availability of serial processes of plastic-pipe manufacturing plant: A case study Int $\mathrm{J}$ Qual Reliab Management 2007,Vol24(4)pp.404-419.

[14] Pari G, Kumar S, Sharma V Reliability improvement of electronics standby display system of modern aircraft Int J Qual Reliab Management Vol. 25 (9) (2008), pp. 955-967

[15] Saraswat S., Yadava G.S., An overview on reliability, availability, maintainability and supportability (RAMS) engineering Int J Qual Reliab Management Vol. 25 (3) (2008), pp. 330344

[16] Vallem, R., \& Saravannan, R. Reliability assessment of cogeneration power plant in textile mill using fault tree analysis .Journal of Failure Analysis and Loss Prevention, (2011). 24,56-70

[17] Sharma K R and Sharma P, Integrated framework to optimize RAM and cost decisions in a process plant, Journal of Loss Prevention in the Process Industries 25 (2012) 883-904

[18] O Connor,' Practical Reliability Engineering',Heden,London,2000

[19] Dhillon BS. 'Engineering Maintainability.' Prentice Hall India, New Delhi, 2004.

[20] Charles E. Ebeling. 'An Introduction to Reliability and Maintainability Engineering.' Tata McGraw-Hill, 2004 